\title{
O ESTADO EM TEMPOS LÍQUIDOS: A ASCENSÃO DAS CORPORAÇÕES TRANSNACIONAIS NA SOCIEDADE GLOBALIZADA
}

\author{
Alessandra Vanessa Teixeira* \\ Francine Cansi** \\ Liton Lanes Pilau Sobrinho***
}

\begin{abstract}
Resumo: O presente estudo analisa o Estado frente à atuação das corporações transnacionais na sociedade globalizada, diante da liquidez que permeia os tempos atuais. Para tanto, iniciase com a reflexão acerca da globalização e da liquidez da sociedade, segue-se expondo sobre o Estado em tempos líquidos, para, ao final, demonstrar a ascensão das corporações transnacionais, a dimensão do seu poder (principalmente econômico) e as consequências geradas diante da sua forma de atuação em todo o mundo. A metodologia a ser empregada compreende o método indutivo, sendo acionadas as técnicas do referente, da categoria, dos conceitos operacionais e da pesquisa bibliográfica.
\end{abstract}

Palavras-chave: Corporações transnacionais; Estado; Globalização; Sociedade; Tempos líquidos.

\section{THE STATE IN LIQUID TIMES: THE RISE OF TRANSNATIONAL CORPORATIONS IN GLOBALIZED SOCIETY}

\begin{abstract}
The present study analyzes the State in face of the performance of transnational corporations in a globalized society, in view of the liquidity that permeates current times. To do so, it begins with a reflection on globalization and society's liquidity, followed by expounding on the State in liquid times, to, in the end, demonstrate the rise of transnational corporations, the dimension of their power (mainly economic) and the consequences generated by its way of acting around the world. The methodology to be used comprises the
\end{abstract}

\footnotetext{
* Doutora em Ciência Jurídica pela Universidade do Vale do Itajaí (UNIVALI). Mestre em Direito pela Universidade de Passo Fundo (UPF). Especialista em Direito Público pela Faculdade Meridional (IMED). Bacharel em Direito pela Universidade de Passo Fundo (UPF). Professora na Faculdade de Ciências Jurídicas de Santa Maria - UNISM. E-mail: alessandra.sp@hotmail.com ORCID iD: https://orcid.org/0000-0001-9658$022 \mathrm{X}$

** Doutora em Ciência Jurídica pela Universidade do Vale do Itajaí (UNIVALI) em Dupla Titulação com o Doctorado en Agua y desarollo Sostenible del Instituto Universitario del Agua y de las Ciencias Ambientales (IUACA), Espanha. Mestre em Desenvolvimento Regional (Unisc/RS). Especialista em Direito e Processo do Trabalho, e Direito Processual Civil. Advogada. Bacharel em Direito Universidade de Passo Fundo- UPF/RS. E-mail: francine@ctmadvocacia.com ORCID iD: https://orcid.org/0000-0002-1434-4862

*** Pós-Doutor em Direito pela Universidade de Sevilha - US - Espanha. Doutor em Direito pela Universidade do Vale do Rio dos Sinos - UNISINOS. Mestre em Direito pela Universidade de Santa Cruz do Sul - UNISC. Professor dos cursos de Mestrado e Doutorado no Programa de Pós-Graduação Stricto Sensu em Ciência Jurídica da Universidade do Vale do Itajaí - UNIVALI. Professor e Coordenador do Programa de PósGraduação Stricto Sensu Mestrado em Direito da Universidade de Passo Fundo - UPF. E-mail: liton@upf.br ORCID Id: https://orcid.org/0000-0001-5696-4747
}

Revista de Movimentos Sociais e Conflitos | e-ISSN: 2525-9830 | Encontro Virtual | v. 7 | n. 2 |

p. $19-39$ | Jul/Dez. 2021. 
inductive method, using the techniques of referent, category, operational concepts and bibliographic research.

Keywords: Transnational corporations; State; Globalization; Society; Liquid times.

\section{Introdução}

A globalização é um fenômeno que provocou e provoca muitas transformações na sociedade. Essa sociedade, por sua vez, é marcada pela fluidez dos acontecimentos, onde tudo está em constante mudança. Diante disso e utilizando-se da teoria de Bauman, pode-se dizer que os tempos atuais são tempos líquidos, permeados por incertezas e inseguranças.

O Estado, nesse contexto, já não traz mais a segurança almejada pela sociedade, diante de vários fatores, mas principalmente diante da ascensão de novos atores no cenário global, destacando-se neste estudo as corporações transnacionais.

Diante disso, o presente estudo pretende analisar o Estado frente à atuação das corporações transnacionais na sociedade globalizada, diante da liquidez que permeia os tempos atuais. Para tanto, inicia-se com a reflexão acerca da globalização e da liquidez da sociedade, segue-se expondo sobre o Estado em tempos líquidos, buscando trazer as causas de seu enfraquecimento, bem como da fragmentação de sua soberania, dentre outros aspectos, para, ao final, demonstrar a ascensão das corporações transnacionais, a dimensão do seu poder (principalmente econômico) e as consequências geradas diante da sua forma de atuação em todo o mundo.

A metodologia a ser empregada compreende o método indutivo, sendo acionadas as técnicas do referente, da categoria, dos conceitos operacionais e da pesquisa bibliográfica. As referidas fontes serão o sustentáculo teórico do trabalho, bem como instruirão a abordagem adotada, permitindo a concretização dos objetivos propostos.

\section{Globalização e liquidez da sociedade}

Os tempos atuais são permeados pela liquidez da sociedade, que gera uma impressionante insegurança existencial - são tempos líquidos. Pode-se dizer, então, que a insegurança é a marca fundamental dos tempos líquido-modernos, outro fenômeno que surgiu com os efeitos da globalização. (BAUMAN, 2007). 
Bauman utiliza a metáfora do sólido e do líquido para explicar sua teoria sobre a modernidade ${ }^{1}$, já que para ele "pós modernidade" é um termo equivocado, uma ideologia ${ }^{2}$.

Sobre a metáfora do sólido e do líquido, o autor explica que os sólidos, diferentemente dos líquidos, se caracterizam por apresentarem uma forma definida, por serem estáveis e duradouros. Já os líquidos não têm forma definida, ou seja, sua forma está em contínua transformação. O líquido é instável por definição, tem uma forma efêmera, passageira e apresenta uma grande mobilidade ${ }^{3}$. O tempo neste estado seria o fator principal da mudança, pois é a urgência de atender as demandas do tempo que tornam as vidas líquidas. (BAUMAN, 2001, p. 8)

A sociedade líquida é marcada pela velocidade dos acontecimentos e pela flexibilidade necessária de adaptação às mudanças ${ }^{4}$. Nesse contexto, Bauman (2001, p. 36) assim a define:

\footnotetext{
${ }^{1}$ Bauman define "modernidade" como: [...] um período histórico que começou na Europa Ocidental no século XVII com uma série de transformações sócio-estruturais e intelectuais profundas e atingiu sua maturidade primeiramente como projeto cultural, com o avanço do Iluminismo e depois como forma de vida socialmente consumada, com o desenvolvimento da sociedade industrial (capitalista e, mais tarde, também a comunista).
} (BAUMAN, 1999, p. 299-300).

2 O autor abandona o termo "pós-modernidade" sob os seguintes argumentos: "Uma das razões pelas quais passei a falar em "modernidade líquida" e não em "pós-modernidade" (meus trabalhos mais recentes evitam esse termo) é que fiquei cansado de tentar esclarecer uma confusão semântica que não distingue sociologia pós-moderna de sociologia da pós-modernidade, "pós-modernismo" de "pós-modernidade". No meu vocabulário, "pós-modernidade" significa uma sociedade (ou, se se prefere, um tipo de condição humana), enquanto "pós-modernismo" refere-se a uma visão de mundo que pode surgir, mas não necessariamente, da condição pós-moderna. Procurei sempre enfatizar que, do mesmo modo que ser um ornitólogo não significa ser um pássaro, ser um sociólogo da pós-modernidade não significa ser um pós-modernista, o que definitivamente não sou. Ser um pós-modernista significa ter uma ideologia, uma percepção do mundo, uma determinada hierarquia de valores que, entre outras coisas, descarta a ideia de um tipo de regulamentação normativa da comunidade humana, assume que todos os tipos de vida humana se equivalem, que todas as sociedades são igualmente boas ou más; enfim, uma ideologia que se recusa a fazer qualquer julgamento e a debater seriamente questões relativas a modos de vida viciosos e virtuosos, pois, no limite, acredita que não há nada a ser debatido. Isso é pós-modernismo. Mas eu sempre estive interessado na sociologia da pós-modernidade, ou seja, meu tema tem sempre sido compreender esse tipo curioso e em muitos sentidos misterioso de sociedade que vem surgindo ao nosso redor; e a vejo como uma condição que ainda se mantém eminentemente moderna na suas ambições e modus operandi (ou seja, no seu esforço de modernização compulsiva, obsessiva), mas que está desprovida das antigas ilusões de que o fim da jornada estava logo adiante. É nesse sentido que pósmodernidade é, para mim, modernidade sem ilusões". (BAUMAN, 2004, p. 301-325).

${ }^{3}$ Bauman diz que "Os fluidos se movem facilmente. Eles "fluem", "escorrem", "esvaem-se", "respingam", "transbordam", "vazam", "inundam", "borrifam", "pingam"; são "filtrados", "destilados"; diferentemente dos sólidos, não são facilmente contidos - contornam certos obstáculos, dissolvem outros e invadem ou inundam seu caminho. [...] A extraordinária mobilidade dos fluidos é o que os associa à ideia de "leveza". [...] Associamos "leveza" ou "ausência de peso" à mobilidade e à inconstância: sabemos pela prática que quanto mais leve viajamos, com maior facilidade e rapidez nos movemos. Essas são as razões para considerar "fluidez" ou "liquidez" como metáforas adequadas quando queremos captar a natureza da presente fase, nova de muitas maneiras, na história da modernidade. (BAUMAN, 2001, p. 8-9).

${ }^{4}$ Para Bauman, essa é a realidade do mundo que ele denomina de "mundo líquido", o qual "jamais se imobiliza nem conserva sua forma por muito tempo. Tudo ou quase tudo em nosso mundo está sempre em mudança: as modas que seguimos e os objetos que despertam nossa atenção (uma atenção, aliás, em constante mudança de foco, que hoje se afasta das coisas e dos acontecimentos que nos atraíam ontem, que amanhã se distanciará das coisas e acontecimentos que nos instigam hoje); as coisas que sonhamos e que tememos, aquelas que 
A sociedade que entra no século XXI não é menos "moderna" que a que entrou no século XX; o máximo que se pode dizer é que ela é moderna de um modo diferente. $\mathrm{O}$ que a faz tão moderna como era mais ou menos há um século é o que distingue a modernidade de todas as outras formas históricas do convívio humano: a compulsiva e obsessiva, contínua, irrefreável e sempre incompleta modernização; a opressiva e inerradicável, insaciável sede de destruição criativa (ou de criatividade destrutiva, se for o caso: de "limpar o lugar" em nome de um "novo e aperfeiçoado" projeto; de "desmantelar", "cortar", "defasar", "reunir" ou "reduzir", tudo isso em nome da maior capacidade de fazer o mesmo no futuro - em nome da produtividade ou da competitividade).

Assim, essa atual sociedade "é cada vez mais vista e tratada como uma "rede" em vez de uma "estrutura" (para não falar em uma "totalidade sólida"): ela é percebida e encarada como uma matriz de conexões e desconexões aleatórias e de um volume essencialmente infinito de permutações possíveis" (BAUMAN, 2007, p. 9).

Depreende-se, portanto, a escolha do "líquido" como metáfora para ilustrar o estado dessas mudanças: facilmente adaptáveis, fáceis de serem moldadas e capazes de manter suas propriedades originais. As formas de vida moderna se assemelham pela vulnerabilidade e fluidez, incapazes de manter a mesma identidade ${ }^{5}$ por muito tempo, o que reforça esse estado temporário das relações sociais.

A globalização, que é o nome dado para a quebra de fronteiras comerciais entre os países, transformou as sociedades em abertas, tanto material como intelectualmente. (BAUMAN, 2007, p. 12). Essa sociedade admite sua incompletude, e por isso, se apresenta “ansiosa em atender suas próprias possibilidades ainda não-intuídas, muito menos exploradas". Porém, significa uma sociedade incompetente em escolher o próprio curso com algum nível de certeza e em assegurar o percurso escolhido. A sociedade aberta traz à maioria

desejamos e odiamos, as que nos enchem de esperanças e as que nos enchem de aflição. As circunstâncias que nos cercam - com as quais ganhamos nosso sustento e tentamos planejar o futuro, aquelas pelas quais nos ligamos a algumas pessoas e nos desligamos (ou somos desligados) de outras - também estão sempre mudando. Oportunidades de alegria e ameaças de novos sofrimentos fluem ou flutuam no ar, vêm, voltam e mudam de lugar; na maioria das vezes, fazem isso com tamanha rapidez e agilidade que não conseguimos tomar uma providência sensata e eficaz para direcioná-las ou redirecioná-las, para conservá-las ou interceptálas. (BAUMAN, 2011, p. 9-10).

5 Bauman explica que "a 'identidade' reserva perigos potencialmente mortais tanto para a individualidade quanto para a coletividade, embora ambas recorram a ela como instrumento de autoafirmação. O caminho que leva à identidade é uma batalha em curso e uma luta interminável entre o desejo de liberdade e a necessidade de segurança, assombrada pelo medo da solidão e o pavor da incapacidade. Por essa razão, as 'guerras de identidade' provavelmente permanecerão inconclusas e, com toda a probabilidade, é impossível vencê-las - a 'causa da identidade' continuará sendo empregada como instrumento, embora camuflada como objetivo". (BAUMAN, 2009, p. 44). 
das pessoas a experiência assustadora de uma população obediente, infeliz e vulnerável, amedrontada pela sua própria vulnerabilidade, sem segurança. (BAUMAN, 2007, p. 13).

Em relação à globalização, então, Beck (1999, p. 46-47) explica que esta

[...] significa a experiência cotidiana da ação sem fronteiras nas dimensões da economia, da informação, da ecologia, da técnica, dos conflitos transculturais e da sociedade civil, e também o acolhimento de algo a um só tempo familiar mas que não se traduz em um conceito, que é de difícil compreensão mas que transforma o cotidiano com uma violência inegável e obriga todos a se acomodarem à sua presença e a fornecer respostas. Dinheiro, tecnologia, mercadorias, informações e venenos "ultrapassam" as fronteiras como se elas não existissem. Até mesmo objetos, pessoas e ideias que os governos gostariam de manter no exterior (drogas, imigrantes ilegais, críticas à violação dos direitos humanos) acabam por encontrar seu caminho.

Nesse contexto, Bauman (1999, p. 68) afirma que "a globalização não diz respeito ao que todos nós, ou pelo menos os mais talentosos e empreendedores, desejamos ou esperamos fazer. Diz respeito ao que está acontecendo a todos nós". Sendo assim, "a globalização não é um acidente em nossas vidas hoje. É uma mudança de nossas próprias circunstâncias de vida. É o modo como vivemos agora" (GIDDENS, 2003, p. 29).

O mesmo autor explica que diante das mudanças e interconexões que têm ocorrido no planeta, ao menos em sua parte mais desenvolvida, está-se criando um "ambiente novo", surgindo assim novos desafios para a sociedade e para os indivíduos. Logo, viver em tempos líquidos é "entrar corajosamente em um viveiro de incertezas”. (BAUMAN, 2007, p. 7).

Nesse contexto, Berggruen e Gerdels (2012, p. 23) salientam que:

La globalización contemporánea ofrece grandes oportunidades pero también presenta enormes desafíos. Aunque la responsabilidad mayor para aprovechar esas oportunidades y superar esos desafíos reside en la políticas y acciones estrictamente nacionales de cada país, también es cierto que para conseguir esos objetivos se requiere de mayor cooperación y coordinación internacionales - tanto para evitar que mucha gente en muchos países quede marginada de los beneficios de la globalización como para resolver problemas que por sua propia naturaleza solo pueden ser atendidos satisfactoriamente midoante la acción colectiva de las naciones -.

Diante do exposto, verifica-se que a liquidez da sociedade se dá pela sua incapacidade de tomar forma fixa, já que se transforma diariamente, tomando as formas que o mercado global impõe. 


\section{O Estado em tempos líquidos}

No mundo globalizado de hoje a sociedade não é mais protegida pelo Estado, ou é pouco provável que confie na proteção oferecida por este. ${ }^{6}$ "O Estado não consegue mais dar respostas minimamente consistentes às sociedades atuais" (CRUZ, 2002, p. 21). Por conseguinte, a sociedade atual está exposta à capacidade de forças que não controla e não espera. Eis o Estado em tempos líquidos.

Nesse contexto, Beck (1999, p. 30) explica que a globalização significa “os processos, em cujo andamento os Estados nacionais vêem a sua soberania, sua identidade, suas redes de comunicação, suas chances de poder e suas orientações sofrerem a interferência cruzada de atores transnacionais". Além disso, significa a "negação do Estado mundial. Mais precisamente: sociedade mundial sem Estado mundial e sem governo mundial. Está se disseminando um capitalismo global desorganizado, pois não há poder hegemônico ou regime internacional econômico ou político" (BECK, 1999, p. 33). (grifos do autor).

Assim, diante do fenômeno da globalização, bem como da separação entre poder e política ${ }^{7}$, sendo esta separação "uma das razões decisivas para a incapacidade do Estado de fazer escolhas apropriadas" (BAUMAN, 2016, p. 22), Bauman (2017, p. 54) diz que "los

\footnotetext{
${ }^{6}$ Neste aspecto, é interessante a colocação de Bauman, que diz que em meados de 1970 "o progresso começou a parar de funcionar, confrontado com o desemprego crescente, a inflação aparentemente incontrolável e a incapacidade crescente dos Estados de cumprir sua promessa de cobertura abrangente. Aos poucos, ainda que de modo cada vez mais grave, os Estados manifestaram a incapacidade de cumprir suas promessas; aos poucos, mas em aparência de forma incontrolável, a fé e a confiança na potência do Estado começaram a se erodir. Funções antes reclamadas e ciosamente guardadas por Estados como monopólio seu, e amplamente consideradas pelo público e pelos formadores de opinião mais influentes obrigações e missão inegáveis dos Estados, de repente pareciam onerosas e vorazes de recursos demais para os Estados-nação suportarem. [...] Na percepção popular, ajudada e encorajada pelo coro de uma parcela crescente do público instruído e formador de opinião, o Estado foi rebaixado da posição de motor mais poderoso do bem-estar universal àquela de obstáculo mais odioso, pérfido e prejudicial". (BAUMAN; BORDONI, 2016, p. 18).

${ }^{7}$ Sobre a separação entre o Poder e a política, Bauman explica que: "Grande parte do poder de agir efetivamente, antes disponível ao Estado moderno, agora se afasta na direção de um espaço global (e, em muitos casos, extraterritorial) politicamente descontrolado, enquanto a política - a capacidade de decidir a direção e o objetivo de uma ação - é incapaz de operar efetivamente na dimensão planetária, já que permanece local. A ausência de controle político transforma os poderes recém-emancipados numa fonte de profunda e, em princípio, incontrolável incerteza, enquanto a falta de poder torna as instituições políticas existentes, assim como suas iniciativas e seus empreendimentos, cada vez menos relevantes para os problemas existenciais dos cidadãos dos Estados-nações e, por essa razão, atraem cada vez menos a atenção destes. Entre ambos, os dois resultados inter-relacionados desse divórcio obrigam ou encorajam os órgãos do Estado a abandonar, transferir ou [...] 'subsidiar' e 'terceirizar' um volume crescente de funções que desempenhavam anteriormente". (BAUMAN, 2007, p. 8).
} 
Estados se están transformando actualmente en no mucho más que vecindarios grandes, circunscritos dentro de unas fronteras vagamente delineadas, porosas e ineficazmente fortificadas" $"$.

O Estado, nos tempos atuais, perdeu grande parte de seu genuíno poder para forças de dimensão global ou supraestatal, cuja operação política se manifesta totalmente sem controle. Com isso, as finanças, os capitais de investimento, os mercados de trabalho e a circulação de mercadorias não são mais somente responsabilidade do Estado. "É a política cronicamente assolada pelo déficit de poder (e, portanto, também de coerção) que enfrenta o desafio de poderes emancipados do controle político" (BAUMAN, 2016, p. 21).

Com as transformações ocorridas na Era Moderna, "falar de crise(s) tornou-se referência ao longo das últimas décadas do Século $\mathrm{XX}$, supostamente frente à desconstrução dos paradigmas que orientaram a construção dos saberes e das instituições da modernidade". Dessa forma, desde aquele tempo muito do que era considerado "sólido" foi se esvaindo, o que refletiu também no enfraquecimento ou crise relativos ao poder da "instituição central da modernidade" - o Estado. (MORAIS, 2002, p. 23)

Nesse quadro, importante ressaltar que a concepção de Estado aqui utilizada parte do Estado moderno ${ }^{9}$ ou, segundo Miranda (2002, p. 32-33), (de tipo) europeu, o qual tem como características próprias a nacionalidade $^{10}$, a laicidade ${ }^{11}$ e a soberania ${ }^{12}$.

Conceituando Estado, Canotilho (2003, p. 89) diz tratar-se de "uma forma histórica de organização jurídica do poder dotada de qualidades, que a distinguem de outros "poderes" e “organizações de poder”. Quais são essas qualidades? Em primeiro lugar a qualidade de poder

8 "Os Estados estão atualmente se transformando em pouco mais do que grandes bairros, circunscritos por fronteiras vagamente delineadas, porosas e ineficazmente fortificadas" (tradução livre).

${ }^{9}$ Ao tratar do Estado moderno como forma histórica determinada, Bobbio, Matteucci e Pasquino, ao utilizar-se de afirmação de Ernst Wolfgang Boeckenfoerde como ponto de partida, referem que "o conceito de 'Estado' não é um conceito universal, mas serve apenas para indicar e descrever uma forma de ordenamento político surgida na Europa a partir do século XIII até os fins do século XVIII ou inícios do XIX, na base de pressupostos e motivos específicos da história europeia e que após esse período se estendeu - libertando-se, de certa maneira, das suas condições originais e concretas de nascimento - a todo o mundo civilizado". (BOBBIO; MATTEUCCI; PASQUINO, 1998, p. 425).

${ }^{10}$ Miranda explica que "o Estado tende a corresponder a uma nação ou comunidade histórica de cultura; o fator de unificação política deixa, assim, de ser a religião, a raça, a ocupação bélica ou a vizinhança para passar a ser uma afinidade de índole nova". (MIRANDA, 2002, p. 32).

${ }^{11}$ Em relação à laicidade (ou secularização), o autor explica que, "por influxo do Cristianismo e ao contrário do que sucede com o Estado islâmico - o temporal e o espiritual se afirmam esferas distintas e a comunidade já não tem por base a religião, o poder político não prossegue fins religiosos e os sacerdotes deixam de ser agentes do seu exercício". (MIRANDA, 2002, p. 32-33).

${ }^{12}$ Para o autor, soberania refere-se ao "poder supremo e aparentemente ilimitado, dando ao Estado não só a capacidade para vencer as resistências internas à sua acção como para afirmar a sua independência em relação aos outros Estados". (MIRANDA, 2002, p. 33). 
soberano" (grifos do autor). Logo, a soberania revela-se nacionalmente como um poder supremo e internacionalmente como um poder independente. Assim, o Estado moderno é definido pelos seus elementos constitutivos que são: o poder político de comando, o povo e o território $^{13}$. (CANOTILHO, 2003, p. 90).

A definição de soberania, segundo Morais (2002, p. 24), se revela e é reconhecida desde os anos 1500, sendo apresentada teoricamente, pela primeira vez, por Jean Bodin, na sua obra “Os Seis Livros da República” (Les Six Livres de la République), em 1576. Desde aquela época vem sofrendo mudanças significativas acompanhando a evolução dos Estados ${ }^{14}$. Dessa forma, a soberania ${ }^{15}$ surgiu como característica fundamental do Estado moderno, significando o poder supremo deste ${ }^{16}$. O autor afirma que

[...] a soberania, caracteriza-se, historicamente, como um poder que é juridicamente incontrastável, pelo qual se tem a capacidade de definir e decidir acerca do conteúdo e da aplicação das normas, impondo-as coercitivamente dentro de um determinado espaço geográfico, bem como fazer frente a eventuais injunções externas. Ela é, assim, tradicionalmente tida como una, indivisível, inalienável e imprescritível. Neste viés, pode-se dizer que a soberania moderna é aquela típica do Estado Nação. Aquela caracterizada por uma estrutura de poder centralizado e que exerce o monopólio da força e da política - legislativa, executiva e jurisdicional sobre um determinado território - como um espaço geográfico delimitado por suas fronteiras - e a população - como um conjunto de indivíduos que é reconhecido como cidadão/nacional - que o habita. (MORAIS, 2002, p. 25)

${ }^{13}$ Da mesma forma, Habermas define juridicamente o conceito de Estado moderno a partir de três pontos de vista: objetivo, quanto ao espaço e social. Assim, objetivamente "[...] refere-se a um poder estatal soberano, tanto interna quanto externamente; quanto ao espaço, refere-se a uma área claramente delimitada, o território do Estado; e socialmente refere-se ao conjunto de seus integrantes, o povo do Estado". (HABERMAS, 2004, p. 129-130).

${ }^{14}$ Morais explica que "o desenvolvimento histórico do conceito de soberania prossegue [...] para, já no século XIX, aparecer como emanação do poder político. Posteriormente, será o próprio Estado, como personalidade jurídica, que deterá a titularidade da mesma, acrescentando-a como uma de suas peculiaridades". (MORAIS, 2002, p. 25).

${ }^{15}$ Nesse aspecto, Bobbio, Matteucci e Pasquino ensinam que: "Em sentido restrito, na sua significação moderna, o termo Soberania aparece, no final do século XVI, juntamente com o de Estado, para indicar, em toda sua plenitude, o poder estatal, sujeito único e exclusivo da política. Trata-se do conceito político-jurídico que possibilita ao Estado moderno, mediante sua lógica absolutista interna, impor-se à organização medieval do poder, baseada, por um lado, nas categorias e nos Estados, e, por outro, nas duas grandes coordenadas universalistas representadas pelo papado e pelo império: isto ocorre em decorrência de uma notável necessidade de unificação e concentração de poder, cuja finalidade seria reunir numa única instância o monopólio da força num determinado território e sobre uma determinada população, e, com isso, realizar no Estado a máxima unidade e coesão política. (BOBBIO; MATTEUCCI; PASQUINO, 1998, p. 1179-1180).

${ }^{16}$ Miranda explica que "O poder político no Estado moderno de matriz europeia não se apresenta isolado, fechado ou dotado de uma expansibilidade ilimitada como noutros tipos históricos; assume sentido relacional pois cada Estado tem de coexistir com outros Estados; pressupõe uma ordem interna e uma ordem externa ou internacional em que se insere; envolve capacidade simultaneamente activa e passiva diante de outros poderes". (MIRANDA, 2002, p. 219). 
Assim, "a moderna ideia de Estado tem o seu expoente na ideia de soberania" (MIRANDA, 2002, p. 37), ou seja, "a soberania constitui, é constitutiva e constituída pela ideia de Estado Nação ou Estado Nacional, próprio da modernidade” (MORAIS, 2002, p. 25).

Para Cruz (2002, p. 7), “O conceito de soberania, historicamente, esteve vinculado à racionalização jurídica do poder, no sentido de transformação da capacidade de coerção em poder legítimo. Ou seja, na transformação do Poder de Fato em Poder de Direito".

Ferrajoli (2002, p. 1-2) busca definir soberania baseado em três "aporias"17, dizendo que se trata de um conceito que é jurídico e político ao mesmo tempo. Segundo o autor, a noção de soberania como poder supremo "remonta ao nascimento dos grandes Estados nacionais europeus e à divisão correlativa, no limiar da Idade Moderna, da ideia de um ordenamento jurídico universal".

As incertezas (aporias) elencadas por Ferrajoli a fim de elaborar a definição de soberania, referem-se: 1) ao significado filosófico da ideia de soberania $^{18}$; 2) à história, teórica e prática, da ideia de soberania como poder supremo (potestas absoluta superiorem non recognoscens $)^{19}$; e, 3) à consistência e à legitimidade conceitual da ideia de soberania do ponto de vista da teoria do direito ${ }^{20}$.

Em tempos líquidos, a soberania do Estado encontra-se fragmentada, já que a "ideia de unidade política soberana do Estado, está hoje relativamente em crise como resultado dos

\footnotetext{
17 "Aporia" é sinônimo de dúvida, incerteza, impasse. Significa incerteza ou hesitação diante do que se pretende dizer. [Retórica] Figura em que o orador simula hesitação no momento em que deve responder. Circunstância sem solução; situação que não se pode resolver. Dificuldade ou incerteza que decorre da impossibilidade de responder uma questão filosófica; dúvida para escolher entre dois pontos de vista racionais, mas contrários. (DICIO, 2020).

${ }_{18}$ Sobre esta primeira aporia, Ferrajoli explica: "Como categoria filosófico-jurídica, a soberania é uma construção de matriz jusnaturalista, que tem servido de base à concepção juspositivista do Estado e ao paradigma do direito internacional moderno; logo, um resquício pré-moderno que está na origem da modernidade jurídica e, simultaneamente, em virtual contraste com esta". (FERRAJOLI, 2002, p. 2).

${ }^{19}$ Quanto à esta segunda aporia, o autor esclarece: "Essa história corresponde a dois eventos paralelos e divergentes: aquele da soberania interna, que é a história de sua progressiva limitação e dissolução paralelamente à formação dos Estados constitucionais e democráticos de direito; e aquele da soberania externa, que é a história de sua progressiva absolutização, que alcançou seu ápice na primeira metade do século XX com as catástrofes das duas guerras mundiais. Nem mesmo cronologicamente as duas histórias coincidem: a da soberania externa iniciou-se primeiro e, diferentemente daquela da soberania interna, ainda está longe de concluir-se e continua a mostrar-se como uma ameaça permanente de guerras e destruições para o futuro da humanidade". (FERRAJOLI, 2002, p. 3).

${ }^{20}$ No tocante à terceira aporia, Ferrajoli sustenta a tese "de uma antinomia irredutível entre soberania e direito: uma antinomia não apenas no plano do direito interno dos ordenamentos avançados, em que a soberania está em contraste com o paradigma do estado de direito e da sujeição de qualquer poder à lei, mas também no plano do direito internacional, em que esta já é contrariada pelas cartas constitucionais hodiernas e, em particular, pela Carta da ONU de 1945 e pela Declaração universal dos direitos de 1948". (FERRAJOLI, 2002, p. 3).
} 
fenómenos da globalização, da internacionalização e da integração interestatal" (CANOTILHO, 2003, p. 90). (grifos do autor).

A partir da teoria do direito, Ferrajoli (2002, p. 40) explica que com a validação dos Direitos Humanos na Declaração de 1948 e também nos Pactos internacionais de 1966 conferiu-se àqueles "um valor supra-estatal, transformando-os de limites exclusivamente internos em limites agora também externos ao poder dos Estados". Dessa forma, a soberania, além de um rompimento em sua dimensão interna por meio do desenvolvimento do Estado constitucional de direito, dissipou-se também externamente diante de um sistema ius cogens, no qual o direito vincula-se de imediato para os Estados-membros. Com isso, além do Estado como sujeito de direito internacional, passam a figurar também os indivíduos e os povos. (FERRAJOLI, 2002, p. 41).

Nesse contexto, Ferrajoli aponta para uma crise (moderna) da soberania. No entanto, ele afirma que "De fato, o que entrou irreversivelmente em crise, bem antes do atributo da soberania, é precisamente seu sujeito: o Estado nacional ${ }^{21}$ unitário e independente" (FERRAJOLI, 2002, p. 45).

Assim, segundo Morais (2002, p. 27-28):

\begin{abstract}
A interdependência que se estabelece contemporaneamente entre os EstadosNação aponta para um cada vez maior atrelamento entre as ideias de soberania e de cooperação jurídica, econômica e social, por um lado, e o de soberania e de intervenção política, econômica e/ou militar, de outro, o que afeta drasticamente a pretensão à autonomia em sua configuração clássica. Por mais que se argumente no sentido de que esta colaboração só é possível em razão da própria soberania, a qual permitiria a um Estado vincular-se a outro(s) em questões que lhe interessem ou para fazer frente a situações paradigmáticas, o que se observa na prática é a revisão radical dos postulados centrais da mesma.
\end{abstract}

Dessa forma, o referido autor destaca o papel fundamental das corporações transnacionais na ordem internacional, já que “impõem atitudes que não podem ser

\footnotetext{
${ }^{21}$ Segundo Ferrajoli, "O Estado nacional como sujeito soberano está hoje numa crise que vem tanto de cima quanto de baixo. De cima, por causa da transferência maciça para sedes supra-estatais ou extra-estatais (a Comunidade Europeia, a OTAN, a ONU e as muitas outras organizações internacionais em matéria financeira, monetária, assistencial e similares) de grande parte de suas funções - defesa militar, controle da economia, política monetária, combate à criminalidade -, que no passado tinham sido o motivo do próprio nascimento e desenvolvimento do Estado. De baixo, por causa dos impulsos centrífugos e dos processos de desagregação interna que vêm sendo engatilhados, de forma muitas vezes violenta, pelos próprios desenvolvimentos da comunicação internacional, e que tornam sempre mais difícil e precário o cumprimento das outras duas grandes funções historicamente desempenhadas pelo Estado: o da unificação nacional e a da pacificação externa". (FERRAJOLI, 2002, p. 48-49).
} 
contrastadas sob o argumento da soberania estatal". Isso porque aquelas empresas não possuem vínculo particular com nenhum Estado e possuem um poder financeiro e de decisão capaz de impactar significativamente a situação de diversos países, principalmente os mais fracos economicamente. (MORAIS, 2002, p. 28-29).

Depreende-se, portanto, que "O Estado soberano moderno, visto como ator privilegiado no cenário internacional, agora divide espaço com novos jogadores. A soberania passa a ser fragmentada, e a tomada de decisão pública passa pela consideração a questões econômicas ditadas pelo mercado" (PILAU SOBRINHO, 2016, p. 114).

Diante dessa fragmentação da soberania no cenário global, Morais (2018, p. 18-20) salienta que "desde algum tempo o tema da "geografia" do Estado tem sido confrontado com algumas questões que afetam diretamente a fórmula estatal da modernidade”, ressaltando a profunda sensibilização da territorialidade, que perde seu significado. Segundo o autor, há uma "perda de limites", levando-o a questionar sobre a ocorrência de um fim da geografia institucional do Estado. Nesse sentido, Morais, então, expõe que

No ambiente dos Estados Nacionais, para o que aqui importa, o que se percebe é uma ruptura da fórmula liberal do Estado de Direito, o que produz um fenômeno que podemos nomear de "fim da geografia institucional", tomando-se aqui o termo geografia para dar o significado de limitação, classicamente incorporado a este modelo, agora no que respeita às possibilidades de atuação da "autoridade pública", como limitação políticojurídica para e ao exercício do poder (político). (MORAIS, 2018, p. 20).

Por conseguinte, o mencionado autor conclui que "o Estado de Direito, como "Estado de limites” já não limita. A sua institucionalidade já não se presta a proteger o cidadão em face de uma autoridade pública que subverte direitos e garantias reconhecidos constitucionalmente" (MORAIS, 2018, p. 20).

Dessa forma, o Estado "vem passando por uma 'mutação empresarial', que se faz com a transposição das normas do mercado para o setor público". Tratam-se de novas regulações, oriundas de atores privados não estatais, muitas vezes transnacionais, que colaboram para as chamadas "fraturas do e no Estado de Direito", como decorrência de uma ação pública construída e compartilhada de forma democrática. (MORAIS, 2018, p. 31).

Neste cenário, Frydman (2018, p. 72), alerta para um atual contexto em que a racionalidade corporativa "pode, sem substituir às regras de direito e de processo, mas 
sobrepondo-se a elas, cumprindo os objetivos de racionalização administrativa, impor-se às garantias jurídicas do Estado de Direito sob o pretexto de reforçar sua eficiência”.

Assim, os "tempos líquidos" vivenciados hodiernamente pelo Estado, são tempos de neoliberalismo ${ }^{22}$, o qual

[...] em sua real complexidade não destrói apenas regras, instituições, direitos. Ele tem uma dimensão prescritiva. Trata-se de uma racionalidade (conjunto de discursos, práticas e dispositivos) que faz da lógica do mercado uma lógica normativa, regendo desde o Estado até o mais íntimo da subjetividade humana. Por meio da generalização da concorrência, como norma de conduta, e da empresa, como modelo de subjetivação, avança como uma razão constitutiva da existência humana: uma nova razão do mundo. [...] sua fratura, sua fragmentação, sua transversalidade por formas e fórmulas regulatórias originadas em lugares diversos daqueles peculiares à esfera pública estatal. (MORAIS, 2018, p. 30)

Diante disso, Bauman (2016, p. 20-21) argumenta que "se deixado a seus próprios mecanismos, os mercados voltados para o lucro levam a catástrofes econômicas e sociais". ${ }^{23}$ $\mathrm{O}$ autor inclusive questiona sobre o dever e a possibilidade de um retorno do Estado aos mecanismos de controle, supervisão, regulação e administração dos mercados; de pronto ele responde que em relação ao dever é uma questão discutível, mas que não é possível, visto que o Estado não é mais o mesmo de cem anos atrás, não dispondo de meios e recursos para tanto.

\footnotetext{
${ }^{22}$ Segundo Piffer, 'O prefixo 'neo', acrescido ao termo liberalismo é a nova roupagem atribuída ao liberalismo clássico, ora reformulado e reavivado. Tal fato ocorreu devido à necessidade de adequar o liberalismo a um contexto marcado por inúmeros acontecimentos históricos oriundos de grandes transformações sociais, políticas e econômicas pelas quais passou o mundo ocidental depois do período da Grande Depressão. [...] o neoliberalismo despontou exatamente no final da Segunda Guerra Mundial". (PIFFER, 2014, p. 43).

${ }^{23}$ Sobre esse aspecto, Ferrajoli afirma que "[...] en el plano politico la globalización se manifiesta como um vacío de derecho público colmado por un pleno de derecho privado producido de forma autónoma, por vía negocial, por los propios actores de la economía. Es claro que los poderes económicos y financieros, en ausência de una esfera pública a su medida, se desarrollan como poderes salvajes, no regulados ya por los ordenamentos estatales sino, por el contrario, en condiciones de orientar las políticas de los estados en su propio beneficio. También en este aspecto se ha invertido la relación entre estado y mercado: ya no son los estados los que garantizan la competencia entre empresas, sino que son las grandes empresas las que ponen a los estados a competir, privilegiando, para sus inversiones, a los países en los que con más facilidad pueden explotar el trabajo, contaminar el médio ambiente y corromper a los gobiernos". "No plano político, a globalização se manifesta como um vazio de direito público preenchido por um direito privado pleno produzido de forma autônoma, por meio da negociação, pelos próprios atores econômicos. É claro que os poderes econômicos e financeiros, na ausência de uma esfera pública que lhes convenha, se desenvolvem como poderes selvagens, não mais regulados por portarias estaduais, mas, ao contrário, em condições de orientar as políticas dos estados em seu próprio benefício. A relação entre o Estado e o mercado também se inverte neste sentido: já não são os Estados que garantem a concorrência entre as empresas, mas sim as grandes empresas que colocam os Estados para competir, favorecendo, para os seus investimentos, os países onde podem explorar o trabalho com mais facilidade, poluir o meio ambiente e corromper governos" (tradução livre). (FERRAJOLI, 2018, p. 20).
} 
Verifica-se, assim, o enfraquecimento ou esfacelamento do Estado $^{2425}$ diante do mercado, ou do poder de outros atores que emergiram no cenário transnacional, notadamente as corporações transnacionais.

\section{A ascensão das corporações transnacionais}

Giddens (1991, p. 66) reconhece que as corporações transnacionais têm o poder de controlar a economia, influenciando sistemas políticos mundiais. Inclusive, as maiores delas, na atualidade, têm orçamentos que ultrapassam os de quase todos os Estados nacionais. ${ }^{26}$ No entanto, o autor afirma que esse poder das corporações transnacionais não compete com o dos Estados quando estão em jogo questões relacionadas à territorialidade e ao controle dos meios de violência. Segundo ele, independente de quão poderosa seja sua economia, "as corporações industriais não são organizações militares (como algumas delas eram durante o período colonial), e não podem se estabelecer como entidades político/legais que governam uma determinada área territorial".

\footnotetext{
${ }^{24}$ No tocante ao enfraquecimento do Estado, Habermas afirma: "O 'enfraquecimento' do Estado nacional faz com que pensemos em primeiro lugar nas modificações constatadas há muito nos sistemas estatais modernos derivados da paz de Vestefália. Os traços desse sistema refletem-se tanto nas determinações do direito internacional clássico como também nas descrições do realismo da ciência política. O mundo estatal é constituído, segundo esse modelo, de Estados nacionais que atuam como atores independentes que tomam decisões mais ou menos racionais - segundo as preferências no sentido da manutenção do poder ou da sua expansão - em meio a uma vizinhança anárquica. Também não muda muito nessa imagem, se os Estados desempenham mais o papel econômico de maximização dos benefícios do que o papel político de acumuladores de poder. Então, decerto, as estratégias cooperativas correspondem melhor ao contexto, mas permanece a aceitação da interação estratégica de poderes atuando de modo independente. Essa imagem convencional nunca foi tão inconveniente quanto na atual situação. Apesar de a soberania e o monopólio da violência da autoridade pública terem permanecido formalmente intactos, a crescente interdependência da sociedade mundial coloca em questão a premissa segundo a qual a política nacional - de um modo geral ainda territorial, nos limites do domínio do Estado - pode ser conciliada com o destino efetivo da sociedade nacional". (HABERMAS, 2001, p. 88-89).

${ }^{25}$ Entendendo que não houve enfraquecimento do Estado soberano ou seu enfraquecimento perante as Corporações Transnacionais, Santos Junior diz: "O Estado não perdeu o poder de constranger as grandes corporações capitalistas, até porque elas continuam dependentes da infra-estrutura estatal para fazer valer seus interesses. [...] O resultado disso é a consolidação de infra-estrutura institucionais que ajustam a ação dos atores internacionais e potencializam seus ganhos. Assim, a tese da globalização segundo a qual no atual sistema poítico internacional, formado por Estados-nação, ocorre um processo irreversível de decomposição do poder desterritorializado em função de agentes extraterritoriais, não encontra sustentação na prática. De fato, dá-se, no presente, o inverso, ou seja, a expansão do sistema político internacional e das funções do Estadonação". (SANTOS JUNIOR, 2007, p. 91).

${ }^{26}$ Nesse contexto, uma recente matéria publicada pela InfoMoney informa que a Apple, considerada hoje a maior empresa de capital aberto do mundo, tornou-se mais valiosa do que o Brasil, superando o PIB brasileiro. A empresa ultrapassou a marca de US\$ 1,88 trilhão em valor de mercado, enquanto o PIB brasileiro foi de US\$ 1,84 trilhão em 2019. (AGÊNCIA ESTADO, 2020).
} 
De acordo com Bakan (2003), as corporações tornaram-se globais/transnacionais e, por isso, os Estados (governos) perderam parte (ou todo) do controle sobre elas. Assim, independente de a corporação ser confiável ou não, nos tempos atuais (líquidos), os Estados não têm sobre elas o poder que possuíam há tempos atrás. Essa é a grande mudança. Os Estados tornaram-se impotentes em comparação com a situação anterior. Diante do capitalismo perverso dominado pelas corporações transnacionais, há a substituição do poder político pelo poder econômico. Assim, os principais protagonistas desse capitalismo têm poder e acessos raros, jamais vistos.

Depreende-se, portanto, que as corporações transnacionais são as responsáveis pelos lucros na economia mundial e, assim, os Estados necessitam de seu sustentáculo. Nesse quadro, estas corporações ditam a maneira de agir do próprio Estado, inclusive quando do desempenho das suas funções básicas. Com isso, seu poder segue crescendo.

Então, nessa sociedade atual descrita por Bauman, a denominada "sociedade líquida", destaca-se a dominação do mercado pelas Corporações Transnacionais.

Sobre isso, Noam Choamski, ao participar do documentário "The Corporation" (ACHBAR; BAKAN; SHANDEL, 2003), diz que a meta das corporações é maximizar o lucro e a participação do mercado. O objetivo para conquistar essa meta é a população. A população precisa ser transformada em consumidores inconscientes de produtos que não desejam. É preciso desenvolver desejos, impor uma filosofia da futilidade, voltar a atenção das pessoas para aspectos fúteis da vida, como o consumo de modismos, por exemplo. Choamski salienta que existem grandes setores da economia, relações públicas e propaganda, que se destinam a encaixar as pessoas no padrão desejado.

Essa é uma das formas de manifestação do poder das corporações transnacionais na sociedade líquida globalizada, haja vista ser uma sociedade de consumidores, onde impera a máxima do individualismo, a busca pela identidade, pela satisfação dos desejos. Nesse aspecto, Bauman (2001, p. 22) destaca:

Para que o poder tenha liberdade de fluir, o mundo deve estar livre de cercas, barreiras, fronteiras fortificadas e barricadas. Qualquer rede densa de laços sociais, e em particular uma que esteja territorialmente enraizada, é um obstáculo a ser eliminado. Os poderes globais se inclinam a desmantelar tais redes em proveito de sua crescente e contínua fluidez, principal fonte de sua força e garantia de sua invencibilidade. E são esse derrocar, a fragilidade, o quebradiço, o imediato dos laços e redes humanos que permitem que esses poderem operem. 
Assim, sob a perspectiva da liquidez da sociedade aliada ao modo de atuação das corporações transnacionais, verifica-se um rompimento de dependência nas relações, principalmente de trabalho, já que, segundo Bauman (2001, p. 171), “A reprodução e o crescimento do capital, dos lucros e dos dividendos e a satisfação dos acionistas se tornaram independentes da duração de qualquer comprometimento local com o trabalho". Por isso o autor diz que o capital acaba por tornar-se extraterritorial e com mobilidade espacial capaz de submeter inclusive agências políticas territoriais aos seus desígnios com a simples ameaça de romper laços e mudar-se para outro local. Em outros termos, no âmbito das corporações transnacionais isso pode significar que o Estado não utilizará seus poderes reguladores para inibir ou restringir as liberdades do capital, na prática funcionando com a baixa de impostos, diminuição das regras, mercado de trabalho flexível e população "dócil” que não ofereça resistência às decisões do capital. (BAUMAN, 2001, p. 172).

Dessa forma, oriundas do fenômeno da globalização, que "define os esforços das empresas no sentido de que estas estejam presentes senão em todo o mundo, pelos menos no conjunto dos mercados tido como estratégicos" (DEFARGES, 1993, p. 54), as corporações transnacionais "son un instrumento de globalización desde el momento en que organizan la producción mundial" (BARBÉ, 1995, p. 197).

A obra "The Corporation" de Joel Bakan (2003), foi inspiração para o filme que ganhou o prêmio de melhor documentário (ACHBAR; BAKAN; SHANDEL, 2003) do Festival de Cinema de Sundance de 2004. Nesta obra, afirma-se que a corporação foi criada por lei para funcionar como uma personalidade psicopata, cujo comportamento destrutivo, se não controlado, leva ao escândalo e à ruína. Há 150 anos atrás, a grande corporação era uma instituição relativamente obscura. Hoje, ela é onipresente, dominante no mundo. Bakan salienta que assim como a Igreja, a Monarquia, o Partido comunista antigamente, a corporação hoje é dominante, governando a vida das pessoas, determinando o que se come, o que se veste, o que se assiste, onde se trabalha, o que se faz.

As corporações transnacionais revelam-se, de acordo com Dowbor (2017, p. 40-41), como sendo o "principal vetor de poder mundial". "Agindo no espaço planetário, na ausência de governo/governança mundial, frente à fragilidade do sistema político multilateral, as corporações manejam grande poder sem nenhum contrapeso significativo". 
Dessa forma, as corporações transnacionais surgem também como instituições de governança dominantes por todo o globo, onde, na maioria das vezes, as maiores delas, abarcam quase todos os países do mundo e ultrapassam os seus governos, seja em relação ao tamanho, seja em relação ao poder. O que impera é o interesse corporativo. Não há que se falar em interesse humano. (KORTEN, 2015).

Constata-se, assim, a presença de uma classe capitalista transnacional, "governada" pelas corporações transnacionais ${ }^{27}$, onde as transformações que geram na economia mundial referem-se ao fato de que produzem mais de um terço do produto industrial mundial e, ademais, uma percentagem muito mais elevada é transacionado por elas, ficando latente a magnitude de seu poder em âmbito global. (SOUSA SANTOS, 2002, p. 32)

A atuação das corporações transnacionais no cenário mundial apresenta aspectos positivos e negativos. Como aspectos positivos Barbé (1995, p. 196) elenca os seguintes: aumentar o volume do comércio mundial; formar capital adicionado para ativar o desenvolvimento; financiar créditos; apoiar o livre comércio e remover as barreiras comerciais; favorecer o desenvolvimento tecnológico; transferir tecnologia para países em desenvolvimento; reduzir custos aproveitando o princípio das vantagens comparativas; gerar emprego; apoiar a formação de trabalhadores; ampliar a oportunidade de compra de novos produtos por meio da internacionalização da produção; globalizar métodos de marketing e publicidade; promover o crescimento nacional e facilitar a modernização nos países em desenvolvimento; gerar bem-estar e riqueza; favorecer as relações pacíficas entre os Estados, que desejam preservar uma ordem que lhes traz riqueza e comércio; quebrar as barreiras nacionais e as regras que regem o comércio internacional.

De acordo com Barbé (1995, p. 196), os aspectos negativos oriundos da atuação das corporações transnacionais são: criar oligopólios que reduzem a competência e a livre empresa; conseguir capital nos países receptores, em detrimento da indústria local e exportar aos países de origem; criar um sistema de devedores e de dependências financeiras;

\footnotetext{
${ }^{27}$ Nesse contexto, Ianni ressalta que "As corporações transnacionais, com frequência apoiadas pelas agências governamentais dos países capitalistas dominantes, e também beneficiadas pelas diretrizes de organizações multilaterais, tais como o Fundo Monetário Internacional e o Banco Mundial, criaram os mais diversos e prementes desafios para as economias socialistas. Além de oferecerem negócios, possibilidades de comércio e intercâmbio de tecnologias, também ofereceram mercados, possibilidades de exportação das economias socialistas para as capitalistas. Aos poucos, as economias centralmente planificadas viram-se estimuladas e desafiadas pelas oportunidades de mercado oferecidas. Aos poucos, a industrialização substitutiva de importações, que predominou em países socialistas, foi acoplada e subordinada à industrialização orientada para a exportação. O que já estava ocorrendo de maneira incipiente em um ou outro país paulatinamente tornou-se um processo contínuo, crescente e avassalador". (IANNI, 2001, p. 61-62).
} 
monopolizar a produção e controlar sua distribuição mundial; exportar a tecnologia não adequada aos países em vias de desenvolvimento; impedir o crescimento da indústria local no Terceiro Mundo, que depende da tecnologia do Primeiro Mundo; criar cartéis que contribuem para gerar inflação; limitar os salários dos trabalhadores; limitar a oferta de matérias primas em mercados internacionais; desgastar culturas tradicionais, criando uma cultura mundial, dominada pelo consumismo; aumentar a diferença entre ricos e pobres; apoiar os regimes repressivos em nome da estabilidade e da ordem; desafiar a soberania nacional e colocar em perigo a autonomia do Estado-nação.

Assim, em relação ao extraordinário poder das corporações transnacionais, Beck (1999, p. 122) salienta que:

\begin{abstract}
Causa espanto verificar que ali onde as empresas transnacionais adquirem a oportunidade de dispor postos de trabalho e impostos no tabuleiro do xadrez da sociedade mundial, elas (como vem acontecendo) maximizam seus lucros e provam os Estados voltados para o bem-estar das oportunidades de configuração e de poder (o que não precisa acontecer intencionalmente). Este exemplo é bastante revelador, pois nele podemos entreler todos os traços distintivos das novas tendências de poder e de conflito entre os atores nacionais e sócio-mundiais. Tudo isto é novo e decisivo, mas não porque estas empresas transnacionais crescem em números e dimensão, mas por caber a elas, dentro do contexto da globalização, a tarefa de jogar os Estados nacionais uns contra os outros (grifos do autor).
\end{abstract}

Dessa forma, Korten (2015) ressalta que as corporações transnacionais mais bemsucedidas do mundo estão envolvidas em um processo de transformação das estruturas do capitalismo global, com o objetivo de consolidar ainda mais seu poder, por meio de complexas formas de organização em rede.

Por fim, diante do exposto, verifica-se que esse imenso poder inerente às corporações transnacionais, embora faça a economia girar, tem muitas consequências negativas para o planeta e para a sociedade, visto que a obsessão em obter lucros entra em conflito com questões ambientais, sociais e humanas.

\title{
5 Considerações Finais
}

O presente estudo buscou analisar o Estado a partir do que se denominou "tempos líquidos", tendo como base teórica, além de Bauman e Bordoni, autores como Canotilho, 
Miranda, Morais, Ferrajoli, dentre outros. Assim, restou claro que o Estado, nos tempos atuais, perdeu grande parte de seu genuíno poder para forças de dimensão global ou supra estatal, cuja operação política se manifesta totalmente sem controle. Com isso, as finanças, os capitais de investimento, os mercados de trabalho e a circulação de mercadorias não são mais somente responsabilidade do Estado.

Evidenciou-se, por meio dos aspectos analisados, o enfraquecimento ou esfacelamento dos Estados, bem como de sua soberania, diante do mercado, ou do poder de outros atores que emergiram no cenário transnacional, notadamente as corporações transnacionais. Dessa forma, percebeu-se que as corporações transnacionais são as responsáveis pelos lucros na economia mundial e, assim, os Estados necessitam de seu sustentáculo. Nesse quadro, estas corporações ditam a maneira de agir do próprio Estado, inclusive quando do desempenho das suas funções básicas.

Dessa forma, a globalização e a liquidez da sociedade se apresentam como propulsionadoras da grandeza das corporações transnacionais que propiciaram domínios nos âmbitos econômicos, financeiros e comerciais, ditando suas próprias regras e regulamentações nesse importante universo global. Com isso, há o enfraquecimento dos Estados, que tem sua soberania ofuscada, dentre outros motivos, pelo imenso poder das corporações transnacionais.

\section{Referências das fontes citadas}

ACHBAR, Mark; BAKAN, Joel; SHANDEL, Thomas. The Corporation. 2003. Disponível em: https://www.youtube.com/watch?v=Zx0f_8FKMrY\&t=45s. Acesso em: 11 ago. 2020.

AGÊNCIA ESTADO. Avaliada em US\$ 1,88 trilhão, Apple supera o PIB do Brasil. InfoMoney, 2020. Disponível em: https://www.infomoney.com.br/mercados/avaliada-em-us188-trilhao-apple-supera-o-pib-do-brasil/. Acesso em: 26 nov. 2020.

BAKAN, Joel. The Corporation: the pathological pursuit of profit and power. New York: Free Press, 2003.

BARBÉ, Esther. Relaciones Internacionales. Madrid: Tecnos, 1995.

BAUMAN, Zygmunt; BORDONI, Carlo. Estado de Crise. Tradução de Renato Aguiar. 1. Ed. Rio de Janeiro: Zahar, 2016.

BAUMAN, Zygmunt. 44 Cartas do mundo líquido moderno. Tradução de Vera Pereira. Rio de Janeiro: Zahar, 2011. 
BAUMAN, Zygmunt. Entrevista com Zygmunt Bauman. Tempo Social, [São Paulo], v. 16, n. 1, p. 301-325, jun. 2004. Entrevista concedida a Maria Lúcia Garcia Pallares-Burke. Disponível em: https://www.scielo.br/pdf/ts/v16n1/v16n1a15.pdf. Acesso em: 21 ago. 2020.

BAUMAN, Zygmunt. Globalização: as consequências humanas. Tradução de Marcus Penchel. Rio de Janeiro: Zahar, 1999.

BAUMAN, Zygmunt. Modernidade e ambivalência. Tradução de Marcus Penchel. Rio de Janeiro: Jorge Zahar, 1999.

BAUMAN, Zygmunt. Modernidade líquida. Tradução de Plínio Dentzien. Rio de Janeiro: Jorge Zahar Ed., 2001.

BAUMAN, Zygmunt. Retrotopía. Traducción de Albino Santos Mosquera. Buenos Aires: Paidós, 2017.

BAUMAN, Zygmunt. Tempos líquidos. Tradução de Carlos Alberto Medeiros. Rio de Janeiro: Zahar, 2007.

BAUMAN, Zygmunt. Vida líquida. Tradução de Carlos Alberto Medeiros. 2. Ed. Rio de Janeiro: Zahar, 2009.

BECK, Ulrich. O que é globalização? Equívocos do globalismo. Respostas à globalização. São Paulo: Paz e Terra, 1999.

BERGGRUEN, Niclolas; GERDELS, Nathan. Gobernanza inteligente para el siglo XXI. Traducción de Federico Corriente Basús y Miguel Izquierdo Ramon. Madrid: Prisa Ediciones, 2012.

BOBBIO, Norberto; MATTEUCCI, Nicola; PASQUINO, Gianfranco. Dicionário de Política. Tradução de Carmen C. Varriale, Gaetano Lo Mônaco, João Ferreira, Luís Guerreiro Pinto Cacais e Renzo Dini. 11. Ed. Brasília: Editora UNB, 1998.

CAnotilho, J. J. Gomes. Direito Constitucional e Teoria da Constituição. 7. Ed. Coimbra: Almedina, 2003.

CRUZ, Paulo Márcio. Soberania, Estado, Globalização e Crise. Novos Estudos Jurídicos Ano VII - $\mathrm{N}^{\mathrm{o}} 15$ - p. 7-24, dezembro/ 2002. Disponível em: https://siaiap32.univali.br/seer/index.php/nej/article/view/323. Acesso em: 28 ago. 2020.

DEFARGES, Philippe Moreau. A mundialização: o fim das fronteiras? Tradução de António Monteiro Neves. Lisboa: Instituto Piaget, 1993.

DICIO, Dicionário Online de Português. Porto: 7Graus, 2020. Disponível em: https://www.dicio.com.br/aporia/. Acesso em: 29 ago. 2020.

DOWBOR, Ladislau. A era do capital improdutivo: por que oito famílias têm mais riqueza do que a metade da população do mundo? São Paulo: Autonomia Literária, 2017. 
FERRAJOLI, Luigi. A soberania no mundo moderno: nascimento e crise do Estado nacional. Tradução de Carlo Coccioli e Márcio Lauria Filho. São Paulo: Martins Fontes, 2002.

FERRAJOLI, Luigi. Constitucionalismo más allá del Estado. Traducción de Perfecto Andrés Ibáñez. Madrid: Editorial Trotta, 2018.

FRYDMAN, Benoit. O fim do Estado de Direito: governar por standards e indicadores. Tradução de Mara Beatriz Krug. Porto Alegre: Livraria do Advogado, 2018.

GIDDENS, Anthony. Mundo em descontrole: o que a globalização está fazendo de nós. Tradução de Maria Luiza X. de A. Borges, 3ª . Ed. Rio de Janeiro: Record, 2003.

HABERMAS, Jürgen. A constelação pós-nacional: ensaios políticos. Tradução de Márcio Seligmann-Silva. São Paulo: Littera Mundi, 2001.

HABERMAS, Jurgen. A inclusão do outro: estudos de teoria política. Tradução de George Sperber, Paulo Astor Soethe e Milton Camargo Mota. 2. ED. São Paulo: Loyola, 2004.

IANNI, Octavio. Teorias da globalização. 9. Ed. Rio de Janeiro: Civilização Brasileira, 2001.

KORTEN, David C. When Corporations Rule the World. Oakland, CA: Berrett-Koehler, 2015.

MIRANDA, Jorge. Teoria do Estado e da Constituição. Tradução da edição portuguesa. Rio de Janeiro: Forense, 2002.

MORAIS, José Luis Bolzan de. As crises do Estado e da Constituição e a transformação espacial dos direitos humanos. Porto Alegre: Livraria do Advogado, 2002.

MORAIS, José Luis Bolzan de. O fim da geografia institucional do Estado. A "crise" do Estado de direito! In: MORAIS, José Luis Bolzan de. (Org.) O "fim" do Estado de direito. 1. Ed. Florianópolis: Tirant Lo Blanch, 2018.

PIFFER, Carla. Transnacionalidade e imigração: a possibilidade de efetivação dos Direitos Humanos dos Transmigrantes diante de Decisões de Regresso na Itália e na União Europeia. 2014. Tese de Doutorado. Universidade do Vale do Itajaí. Disponível em: https://www.univali.br/pos/doutorado/doutorado-em-ciencia-juridica/banco-de- teses-comdupla-titulacao/Paginas/default.aspx. Acesso em: 01 jul. 2020.

PILAU SOBRINHO, Liton Lanes. A crise da globalização e o desafio de uma governança sustentável. In: DEMARCHI, Clóvis; OLIVEIRA NETO, José Francisco Oliveira de; ABREU, Pedro Manoel. Direito, Estado e Sustentabilidade [livro eletrônico]. São Paulo: Intelecto Editora, 2016. 
SANTOS JUNIOR, Raimundo Batista. A globalização ou o mito do fim do Estado. Ijuí: Unijuí, 2007.

SOUSA SANTOS, Boaventura de. A globalização e as ciências sociais. São Paulo: Cortez, 2002. 